\title{
Methodology based on best practice rules to design a new-born trochoidal-gear pump
}

\author{
P. J. Gamez-Montero, R. Castilla and E. Codina
}

\begin{abstract}
The trochoidal-gear pump, also known as gerotor, owing to its remarkable advantages in front other hydraulic pumps is chosen for many engineering applications. As each application is unique, the designer ought to be knowledgeable of the required specifications as a first task but could not be an expert in hydraulic pump design. The review of existing research reveals significant gaps to develop a new-born project and the work presented in this paper, drawn on existing research work and the own authors' experience and know-how, aims to overcome them. Then, the objective of the paper is to provide a summary of best practice rules to design a trochoidal-gear pump from scratch achieving a thorough understanding. In the conceptual stage, making decisions come according to a predetermined set of four parameters known by the designer that will lead to the complete development of the trochoidal-gear set.
\end{abstract}

\author{
LABSON, Department of Fluid Mechanics \\ Universitat Politecnica de Catalunya \\ Colom 7, 08222 Terrassa, Spain \\ Corresponding author: \\ P.J. Gamez-Montero, LABSON, Department of Fluid Mechanics \\ Universitat Politecnica de CatalunyaColom 7, 08222 Terrassa, Spain \\ Email: pjgm@mf.upc.edu
}


Proc IMechE Part C: J Mechanical Engineering Science

\begin{abstract}
Afterwards, in the design process, the most important characteristics of the pump such as the porting, the pump construction and the limitations are presented based on significant explanations, meaning of each feature, selection, effects and good practices. As a result, the methodology presented compiles the process of engineering design a new trochoidal-gear pump as a catalog of guidelines aiming to overcome a vague design due to a lack of knowledge. This collection of best practice rules intends to guide the designer taking good decisions early in the design process that limit design change later in the final stage: the prototype.

Keywords
\end{abstract}

Gerotor, design methodology, pump porting, pump construction, pressure balance

\title{
1. Introduction
}

The process of engineering design a new trochoidal-gear (gerotor) pump to perform required specifications intrinsically involves making a series of good decisions, specially if this process starts at the very beginning, from scratch. In the conceptual stage, making decisions come according to a predetermined set of parameters, mainly volumetric flow rate and dimensional constraints. Afterwards, early in the design process, operating conditions, performance and power/weight ratio become the key parameters that will lead to the final stage of the design process: a prototype.

By reviewing literature over the current century, a great amount of work have been published related to trochoidal-gear machines, as in Ivantysyn and Ivantysynova ${ }^{1}$. 
Nevertheless, few works are presented related to design analysis, otherwise related to simulation approach ${ }^{2-4}$. Then, as far as authors' knowledge by means of their available public bibliography, there is neither a methodology nor a summary published in any journal yet that compiles the process of engineering design a new trochoidal-gear pump as a catalogue of the best practice rules aiming to overcome a vague design due to a lack of knowledge. This paper is intended to offer "a bridge" between data sheet commercial literature to specialized bibliography for those beginners in trochoidal-gear pump technology.

The technology of trochoidal-gears pumps progresses towards an important number of sectors such as life science, industrial and mechanical engineering. Here, recent paradigm, as environmental concerns, shifts in the industry in additional applications leading to growing demand for pumps that can improve their efficiency. Then, the new progressive topics related to trochoidal-gear pumps are mainly numerical approaches corroborated with experimental work in existing units. In order to step forward to accomplish such requirements at the conceiving stage, a methodology based on a summary of best practice rules to design a trochoidal-gear pump from scratch is presented in this paper. This summary intends to guide the designer taking good decisions 
early in the design process that limit design change later in the experimental and manufacturing part. This work draws on existing research work and the own authors' experience and know-how.

The methodology presented in this paper is specifically applied to a trochoidal-gear set where the internal gear profile is a modified epitrochoid and the external gear profile is a modified envelope with circular arc teeth. Analysis of other kind of trochoidal profiles related to performance indexes such as flow rate, flow irregularity, efficiency, specific sliding and pressure angle of circular or noncircular generating curves and combined multiple profiles can be found ${ }^{5-9}$.

Despite of the enormous great work and research carried out in the last decade regarding to trochoidal and teeth profile, there is not an specific trochoidal profile that assembles the best and optimized characteristics yet ${ }^{10-12}$. Other geometric approaches for a new tooth profile and innovative design to develop high efficient trochoidal-gear pump can be found ${ }^{13-15}$.

Also, the methodology presented in this paper is not intended for being applied to mini $(<20 \mathrm{~mm})$ and micro trochoidal-gears $(<5 \mathrm{~mm})$ owing to geometry scale factor, 
kinematic and fluid dynamics ${ }^{16-17}$. Finally, it is related to constant volumetric displacement ${ }^{18}$.

The structural formatting of the paper is based on consecutively sections presenting the methodology and inside of each section, the corresponding summary of the best practice rules.

\section{A new-born trochoidal-gear pump project}

The remarkable growth of using trochoidal-gear pumps in numerous engineering applications is mainly based on its advantages summarized as follows,

A. Simplicity: (i) the fewest components of any type of pump, (ii) the least amount of machining, (iii) plain configuration that allows working with a relatively simple design and (iv) no dynamic sealing and no bearings.

B. Versatility: (i) the trochoidal-gear can be manufactured of varied materials, (ii) working with an important variety of fluids, (iii) mounted directly on an existing shaft, (iv) bidirectional pumping, (v) quick response to new operating conditions and (vi) the size and geometry can be optimized for performance saving weight and minimizing power loss. 
Proc IMechE Part C: J Mechanical Engineering Science

C. Performance: (i) optimal volumetric characteristics with an excellent efficiency/size ratio, (ii) lower flow irregularity of any type of rotary displacement pump and (iii) long service life because the relative velocity between the inner and outer gear is very low.

The best design of trochoidal-gear pump strikes a balance between volumetric efficiency, manufacturability and mechanical efficiency. Every effort shall be made to match the best gear form, material and manufacturing process to meet the specific application requirements. The challenge in the design of a trochoidal-gear pump must principally comply with the following constraints:

- Displacement. To be consequent to the volumetric flow rate demand.

- Space. The pump may only occupy the space allotted from the manufacturer.

- Speed. It shall operate over a wide speed range.

- Noise. The pump must not significantly contribute to radiate noise.

- Power losses. The pump should not detrimentally affect the energy consumption. 
- Fixed volumetric displacement. At high speed, the volumetric flow rate is in excess of the engine demand, and a relieve valve is necessary.

\title{
3. The conceptual stage: the trochoidal-gear set
}

\begin{abstract}
As trochoidal-gear pump specifications become more demanding and design cycles shorter, the conceptual stage is based on the achievement of the following three factors being a cost effective and valuable guide to a more effective design process.
\end{abstract}

1. Characterization of the system: (i) analysis of the system, (ii) establish the system requirements, (iii) knowledge of operating conditions: volumetric flow rate, working pressure, fluid temperature, type of fluid and prime mover and (iv) total length and dimensions of suction/inlet and discharge/outlet pipe.

2. Pump on request: (i) minimum volumetric flow rate, (ii) maximum pump pressure, (iii) pump speed, (iv) volumetric efficiency demands, (v) worst case flow condition: low speed + high pressure + high temperature, (vi) worst case power condition: high speed + high pressure + low temperature and (vii) maximum and minimum liquid temperature when entering the pump. 
Proc IMechE Part C: J Mechanical Engineering Science

3. Dimensional constraints: (i) easy to house within a cylindrical bore/casing, (ii) external diameter of the outer gear, (iii) thickness of the trochoidal-gear set, (iv) number of teeth and (v) weight and volume and its ratio are restrictions on design.

All three factors are fundamental and, as each application is unique, it is the first task of the designer to achieve all the points and specifications before to go further in the conceptual stage.

\subsection{The volumetric capacity and dimensional constraints parameters}

The characterization of the system will set up the volumetric flow rate and, as a consequence, the volumetric capacity $c_{v}$ in $\left[\mathrm{cm}^{3} / \mathrm{rev}\right]$. Then, the dimensional constraints will set up the trochoidal-gear thickness $H$ in $[\mathrm{mm}]$ and the external diameter of the outer/external gear $D_{c}$ in [mm] (see Figure 1). The gear thickness is proportional to the volumetric capacity. However, the main influence of $H$ is related with the filling capability of the chambers, and subsequently, on the volumetric performance and efficiency. Such behaviour can be explained considering that with high values of $H$ the fluids must travel for a longer axial distance to reach the bottom of the chamber. 
Figure 1. The basic geometrical parameters of the trochoidal-gear.

Then, the eccentricity $e$ in $[\mathrm{mm}]$ of the trochoidal-gear set, which is the most difficult geometrical parameter to predict, can be calculated by using a heuristic approach to the equation,

$$
e^{2}-\left(\frac{D_{c}}{4}-\frac{w c}{2}\right) e+\frac{39.8 \cdot c_{v}}{H}=0
$$

where $w c$ in $[\mathrm{mm}]$ is the wall wide of the outer/external gear (see Figure 1). The value of wc can be estimated by using the following expression,

$$
w c=0.075 \cdot D_{c}
$$

being just an estimation because it is not taking into account the number of teeth of the external gear, working pressure, contact stress and gear material ${ }^{19-21}$.

The eccentricity must be limited to a certain value in order to avoid the formation of cups and loops as presented by Choi et al. ${ }^{22}$ Moreover, the eccentricity is related to the number of chambers, in other words, related to the number of teeth of the external gear. To further increase the eccentricity it is necessary to reduce the number of chambers. Altare and Rundo ${ }^{23}$ show that the reduction of the chambers can slightly improve the volumetric 
efficiency, but also can negatively influence the flow ripple increasing the irregularity flow index.

Now, the arc radius of the external gear tooth $S$ in $[\mathrm{mm}]$ can be calculated as:

$$
S=\frac{Z \cdot e}{\lambda}-0.995\left(0.5 \cdot D_{c}-w c\right)+2 \cdot e
$$

where $Z$ is the number of teeth of the external gear and $\lambda$ is the tooth profile height correction coefficient - function of the eccentricity, the number of teeth, the arc radius of the outer gear tooth and the tip diameter of the internal gear - with recommended values going from 0.6 (larger $S$ ) to 0.8 (shorter $S$ ) from Stryczek et al. ${ }^{24}$

\subsection{The number of teeth and the number of chambers}

The number of teeth of the external gear and the internal gear $(Z-1)$ directly affect performance and size. With regard to the performance, a flow ripple is generated mainly by the pumping mechanism, independent of the dynamic characteristics of the circuit to which the pump is connected but interacting in a complex manner to produce a pressure ripple, also known as fluid-borne noise. This flow ripple can be minimized with careful attention to pump design, as housing clearances, manufacturing tolerances, trochoidalgear geometry and pump porting. With regard to the size if the gear thickness wants to be 
reduced at equal space constraints and still provide the same volumetric capacity, it is necessary to reduce the number of chambers, accordingly, the number of teeth of the external gear.

Then, summarizing, trochoidal-gears of identical theoretical volumetric capacity will present:

- Advantages of increasing the number of teeth/chambers are: (i) lower flow ripple, smaller chambers, (ii) large internal diameter on the inner gear which accommodates thru-shaft applications and (iii) less contact stress, distributed in more contact points.

- Advantages of diminishing the number of teeth/chambers are: (i) smaller size, smaller external diameter of the outer gear, (ii) less power loss, less contact points and (iii) higher operating speed, smaller tip velocity of the internal gear.

- Drawbacks of increasing the number of teeth/chambers are: (i) worse chamber filling and (ii) more restrictive flow passageway. Looking at trochoidal-gear sets with different number of chambers but with identical external diameter of the outer gear, gear thickness and volumetric capacity, it can observe a reduction in axial velocity (filling velocity) as the number of chambers decrease. Mancò et al. ${ }^{25}$ 
demonstrate that the number of chambers influences the variation of the lateral surface as well as the restrictive flow passageway of the chamber area.

- Drawbacks of diminishing the number of teeth/chambers are: (i) higher flow ripple, with bigger chambers, and (ii) higher contact stress, distributed in less contact points.

In general, a trochoidal-gear set with an even number of the teeth of the internal gear typically has a lower flow ripple than a trochoidal-gear set with an odd toothed internal gear having one more tooth as shown by Mancò et al. ${ }^{25}$. As a best practice rule, a range of values of teeth between 5 up to 11 is recommended for the outer gear.

\subsection{The trochoidal profile}

Then, by knowing $c_{v}, H$ and $D_{c}$ from the specifications of the application, and by choosing $Z$ with the criteria exposed in the previous lines, the four basic parameters are defined and the designer can use the well-known formulae to calculate the trochoidal profiles of the inner gear ${ }^{26}$. In addition, these parameters can be introduced in specialized free software that will calculate and provide the designer with the technical drawings in CAD format ${ }^{27-28}$. 


\subsection{The theoretical outputs}

The theoretical torque $T$ in $[\mathrm{N} \cdot \mathrm{m} / \mathrm{bar}]$, theoretical power $N$ in $[\mathrm{W} / \mathrm{bar} \cdot \mathrm{rpm}]$, the tip velocity of the internal gear $V t$ in $[\mathrm{m} / \mathrm{s} \cdot \mathrm{rpm}]$ and the theoretical radial load $R L$ in [N/bar] can be estimated by using the following expressions:

$$
\begin{gathered}
T=0.016 \cdot c_{v} \\
N=0.0016 \cdot c_{v} \\
V t=0.0001 \cdot\left(\frac{D_{c}}{2}-w c-e\right) \\
R L=0.1 \cdot H \cdot\left(D_{c}-2 \cdot w c-3 \cdot e\right)
\end{gathered}
$$

$R L$ value is a reference to the load on the shaft and its bearings, and $V t$ value must be taking into account regarding to the volumetric efficiency since the increase of $V t$ has a negative effect on the filling capability of the chambers.

\section{The design process: the pump}

\subsection{The porting}

The theoretical porting is based on the contact points where a chamber is comprised between two successive contact points $\left(P_{1}\right.$ and $P_{2}$ in Figure 2$)$ : the maximum chamber area (Figure 2(a)) from end inlet port $(f a)$ to the beginning outlet port (ii), and the 
minimum chamber area (Figure 2(c)) from end outlet port (fi) to the beginning inlet port (ia). As an example, the restricted flow passageway as effective port area is shown in Figure 2(b) in the outlet port.

Figure 2. The function of the porting.

The function of the porting is also related to the number of chambers. A low number of chambers, besides increasing flow irregularity, also limit the angular extent of the inlet phase $\chi_{\text {inlet }}$ (Figure $\left.2(\mathrm{~b})\right)$. The angle $\Delta \chi_{\max }$ sets the position of maximum chamber area (Figure 2(a)) where will be no by-pass flow from outlet to inlet port. But if there are few chambers it is necessary to increase angle $\Delta \chi_{\max }$ that identifies the end inlet port $(f a)$. Accordingly, the angular span during which the chamber is connected to inlet port is reduced affecting the filling capability. In addition, with few chambers, the restricted flow passageway starts when chamber volume variation is still high whereas with many chambers this occurs when the rate of change of volume has become sufficiently low. Owing to these remarks and as a best practice rule, the end of inlet port becomes the more important the lower is the number of chambers ${ }^{25}$. 


\subsubsection{The theoretical and the former porting}

The porting located at the housing on the casing is an important factor in the trochoidalgear pump volumetric performance and efficiency and a proper porting design requires experience and knowledge by the pump designer. There are several options for pump porting, depending on the performance requirements, application and manufacturing considerations. As minimum requisites of the geometry of porting must $(A)$ not reduce the face sealing provided by the wall wide of the outer gear (B) provide the best chamber filling as possible $(\mathrm{C})$ provide the best sealing to avoid leakage as possible.

(a)

(b)

Figure 3. The theoretical porting $(a)$ and the former porting $(b)$.

The theoretical porting is depicted in Figure 3. The external porting radius $G$ in $[\mathrm{mm}]$ and the internal porting radius $R i R i$ in $[\mathrm{mm}]$ can be calculated as:

$$
\begin{gathered}
G=0.5 \cdot D_{c}-w c \\
R i R i=0.5 \cdot D_{c}-w c-3 \cdot e
\end{gathered}
$$


and the upper limit, the porting angle, and the lower limit, the porting length, can be simply obtained by calculating the corresponding contact points $\left(P_{i a}, P_{f a}, P_{i i}\right.$ and $\left.P_{f i}\right)$ by means of the line of contact ${ }^{26-28}$.

The theoretical porting does not accomplish the minimum requisites, specially providing the best chamber filling as possible, and a former porting is then proposed and depicted also in Figure 3. Reducing the porting length, the direct communication between outlet port (high pressure) with the inlet port (low pressure) is ensured. Moreover, the inlet angle is a delayed angle from the theoretical porting angle at the inlet port that will guarantee a better chamber filling by delaying the restricted flow passageway. Simultaneously, the outlet angle is a delayed angle from the theoretical porting angle at the outlet port that will avoid an undesirable back pressure rise in the maximum area chamber and back to the inlet port. Moreover, if the chamber is connected with the outlet port in the decreasing chamber volume phase before closing with the inlet port, the fluid is backward flowed while the volume decreases causing a flow loss of the pump. Then, such situation should be excluded at the design stage of the porting.

As a best practice rule, the outlet angle can be set between $50 \div 60$ and the inlet angle between $30 \div 4$, without ignoring that at high working pressure and low viscosity working 
fluid, a better design is required of the former porting and eventually could be not enough demanding metering porting to be machined.

\author{
4.1.2. The metering porting \\ When outlet and inlet metering grooves are design specifically different, the pump \\ rotation must be unidirectional.
}

The inlet metering groove shown in Figure 4 adopts a shape of an arc radius of value $S$ and will provide an angular extent of the inlet phase improving filling capability (see Figure 6 (a)). Moreover, the inlet metering groove allows a reduction in fluid velocity in the axial direction at the end of the inlet phase and this convenient situation is the more marked the lower (e.g. 5-6) is the number of chambers. Mancò et al. ${ }^{25}$ corroborate that if these are numerous (e.g. 10-11) the difference between velocities tends to diminish.

On the other hand, when the maximum volume chamber is suddenly exposed to the outlet port, the high and strong periodic increase of pressure negatively affects the pump performance. The outlet metering groove shown in Figure 4 can reduce the rate of pressure rise, and the resulting fluid-borne noise and fluid-borne vibration, strategically locating it when the chamber volume rate is close to zero (see Figure $6(a))$. The pressure 
Proc IMechE Part C: J Mechanical Engineering Science

pulsation is also increased with the rotation velocity and its effect can be sufficiently decreased by progressively increasing the groove width from the outlet angle to the metering outlet angle so that the opening areas between the chamber and the ports are extended.

The metering porting sizing varies from one trochoidal-gear to another. As guidelines, the maximum porting length is calculated by using the coordinates of the contact point at the end of the delivery port $\left(\mathrm{P}_{\mathrm{fi}}\right)$ and the coordinates of the contact point at the beginning of the inlet port $\left(\mathrm{P}_{\mathrm{ia}}\right)$. The minimum meeting inlet angle can be evaluated locating the beginning of arc radius $S$ of the outer gear. The maximum metering outlet angle should end in the contact point $P_{\text {moa }}$ shown by Gamez-Montero et al. ${ }^{26,29}$

Figure 4. The outlet and the inlet metering porting.

As an inconvenient it can be mention the increased complexity to machine with metering porting. However, nowadays, with the existing materials and machining processes, this is less of an issue. 


\subsubsection{The porting depth}

The depth of the former porting should be such that it does not restrict the pump flow, especially on the inlet side ${ }^{25}$. As a best practice rule, Kim et al. ${ }^{30}$ propose a port depth equal to the trochoidal-gear thickness is adequate and the effect of the fluid inertia on the pressure pulsation will be minimized.

The port depth varying according to its length at the end of the outlet port and at the beginning of inlet port is thought to diminish the transversal section of port when the chamber is reaching the minimum area (see Figure 5). This strategy is conceivable to counteract the flow reduction effect. Then, the axial velocity and the draw back velocity are better controlled and less backward flow is produced when the minimum chamber reaches the porting length ${ }^{28}$. The port depth variation can be determined by the chambers effective port area variation ${ }^{28}$. In the outlet metering groove porting, the depth varying according to its length is conceivable to make pressure variations in the pump more stable. A typical value of the angle indicated in Figure 5 is around $20 \div 25$ o for a convectional trochoidal-gear pump of external diameter of the outer gear between 70 and $80 \mathrm{~mm}$. 
Proc IMechE Part C: J Mechanical Engineering Science

Figure 5. The porting depth variation.

\subsubsection{The shadow porting}

A light version of the porting, on the opposite side of the housing and carved on the cover plate, is recommended to help axial pressure balance preventing unwanted thrust loads, and to help filling the chambers from both lateral sides creating a double filling (see Figure $6(b))$. The shadow porting will have the same external and internal porting radii but should be increased the porting angle and porting length to prevent any accidental crossporting leakage that could result from angular misalignment. When metered shadow porting is employed, a shadow outlet metering groove is not usually required. As best practice rule the depth of the shadow ports can be $10 \div 20 \%$ of the port depth, commonly from 0.5 to $3.0 \mathrm{~mm}$. In addition, it is worth to highlight that the depth of the shadow port on the inlet side can be higher, in order to feed the chambers from both sides.

(a)

(b)

Figure 6. The metering porting $(a)$ and the shadow porting on the cover plate $(b)$ where an inlet meeting groove is also machined. 


\subsection{The pump construction}

The most common methods of construction of a trochoidal-gear pump are the two-piece efficient-method and the three-piece tight-method.

The two-piece efficient-method is a cost effective construction, which employs an eccentrically machined housing on the casing for the trochoidal-gear and a cover plate. The three-piece tight-method is a precise construction that employs a centerplate, an eccentric ring located between the casing and the cover plate. The centerplate establishes the eccentricity of the pump and must be precisely located relative to the shaft. In applications where a tight axial clearance is required, the centerplate can be ground or lapped to thickness for better control of the axial clearance between the trochoidal-gear and the cover plate. As a best practice rule, the material of the centerplate can be closely matched to the trochoidal-gear, thereby ensuring constant axial clearance, and being less sensitive to temperature changes.

\subsubsection{The pressure balance}


The internal diameter located in the inner gear accommodates the shaft and drives the inner gear. If the leakage flow across the face to the shaft is not adequately drained axial pressure develops. If this back pressure differs from one side of the gear to the other and cannot be compensated, a thrust load can develop that will force the gear against one face and may cause high torques or even a seizure. Then, a passageway form the end of the shaft pocket to the inlet port is recommended.

As a best practice rule, the internal diameter of the inner gear compromises of large value to prevent face friction and wear, and small value to avoid leakage flow across the face and deformation with the driving torque.

The inlet and outlet porting can compensate radial pressure imbalance and reduce metalto-metal contact and frictional force. This compensation is also recommended to help pressure balance and reduce viscous losses by improving hydrodynamic lubrication between gear thickness and the housing.

The outlet porting pressure force acting through the inner gear (red-continuous line with red arrows depicting pressure force projection on the inner gear in Figure 7) is compensated by extracting the wall where the outer gear is guided in its rotation movement (blue-dashed line depicting the absence of the wall outer diameter in Figure 7). 
Consequently, an important reduction of the contact force, and hence frictional force, is achieved. Moreover, by extracting a part of the wall outer diameter in both ports, the pressure is compensated by allowing communicating both sides of the gear through the ports (small-squared red-hatched area of the outlet port and big-squared blue-hatched area of the inlet port in Figure 7).

Figure 7. The pressure imbalance.

\subsubsection{The recirculation path}

The recirculation path will recirculate flow from the outlet to the inlet port to promote a local pressure rise in the pump inlet port. Then, a better filling is achieved, cavitation is minimized and the pump can operate at rotational speeds greater than normally recommended. The recirculation path must act where the chamber exhibits the highest flow passage area prior to the intervention of the rim of the porting that will decrease the effective flow area. 
Proc IMechE Part C: J Mechanical Engineering Science

\begin{abstract}
4.2.3. The undercut
In the pump construction design, specially in the two-piece efficient-method, is strongly recommended to add an undercut to the bottom of the housing on the casing where the trochoidal-gear is located, or a specific chamfer on the external diameter of the outer gear, to avoid any interference in that area as shown in Figure 8. This undercut, together with the chamfer, allow introducing the iron filings and any tiny solid particles generated when the trochoidal-gear runs on the housing and prevents scratches, wear and erosion. As a best practice rule, indicative values of undercut and chamfer are presented in Figure 8.
\end{abstract}

Figure 8. The undercut in the housing and the chamfer in the gear [mm].

\title{
4.2.4. The clearances
}

The most important factors affecting pump performance are the pump clearances.

Despite of that tolerances in a pump design are dependent upon each application, Table 1 intends to provide a basic guidelines of clearances ${ }^{3,31}$. 
Table 1. Basic guidelines to conventional operating conditions and clearances.

\begin{tabular}{lll}
\hline Parameter & Low Pressure & High Pressure \\
\hline Pressure [MPa] & $0.3 \div 1.0$ & $1.0 \div 6.0$ \\
Rotational velocity [rpm] & $500 \div 10000$ & $1500 \div 3500$ \\
Volumetric capacity [cc/rev] & $3.0 \div 15.0$ & $9.0 \div 20.0$ \\
Axial face clearance [mm] & $0.05 \div 0.10$ & $0.005 \div 0.030$ \\
Tip-to-tip clearance [mm] & $0.08 \div 0.20$ & 0.08 max. \\
Eccentricity tolerance [mm] & \pm 0.05 & \pm 0.02 \\
External outer diameter clearance [mm] & $0.10 \div 0.20$ & $0.08 \div 0.14$ \\
\hline
\end{tabular}

The tip-to-tip clearance is of great importance. As shown in Figure 9, while in A flanks are engaged, in the maximum chamber area position $B$ a much more critical situation exists owing to the clearance in the tip-to-tip partnering of two teeth as is explained by Mancò et al. ${ }^{16}$ New designs in the porting can compensate the tip-to-tip clearance at the maximum chamber volume position by using an outlet pressure with the appropriate location of a special rim that generates an extra pressure force reducing clearances (red arrows in Figure 9).

Figure 9. The special rim that generates an extra pressure force reducing clearances. 
Proc IMechE Part C: J Mechanical Engineering Science

\begin{abstract}
Owing to the importance of the clearance effects, Ivanovic et al. ${ }^{32}$ and Hsieh ${ }^{33}$ propose variable clearance designs that maintain robust flow characteristics and effectively reduce shock and collision among pump components, reducing stress level and increasing stability.
\end{abstract}

\title{
4.2.5. The inlet and outlet pipe direction
}

By taking as a reference the angle between the axis of the pipe and the axis of the shaft $\left(0^{\circ}\right.$ indicates that the direction of the fluid in the pipe coincides with the tangential velocity of the chambers), better results are obtained with the axial feeding of the inlet and outlet pipes into the corresponding ports, which corresponds to the minimum deviation of the fluid flow to enter the chambers ${ }^{23}$. However, angles lower than $90^{\circ}$ are generally acceptable.

\author{
4.2.6. The materials and the surface roughness \\ The material for the pump casing and cover should be chosen with the following \\ properties in mind:
}


- Wear: wear properties of the material are important owing to that with high temperature, high pressure, low speed, and low viscosity conditions there could be metal-to-metal contact.

- Thermal expansion: extreme-working conditions, such as high temperature, can increase the axial clearance of the pump during operation, and a cooling system becomes an essential aspect in coordination with the entire system via the selection of components. On the contrary, in very cold conditions, differences in thermal expansion can reduce axial clearances to zero and cause pump seizure at start-up. Then, material selection, in both pump housing and trochoidal-gear, becomes the essential aspect.

- Stiffness: stiffness properties can increase the axial clearance of the pump during operation. In some applications, cover plate deflection on some pumps could be similar to the allowable axial clearance.

- Coatings: Coatings can play an important role in the trochoidal-gear performance in the pump. In some cases PTFE coatings applied to anodize rotors are intentionally manufactured without clearance, then 'run in' to wear the coatings back to a running clearance. On the other hand, any debris collected during normal 
Proc IMechE Part C: J Mechanical Engineering Science

running should preferably be able to pass through the pump without damaging the rotor surfaces or shafts, so a degree of clearance between rotor tips can be desirable.

\begin{abstract}
A list of materials is: trochoidal-gear (sintered metal, powdered metal, steel, stainless steel, ceramics, tungsten carbide Ni-based, alloy C, alloy 20 , alloy $\mathrm{C} 22$, thermoplastic injection moulded, PEEK, POM, PPS, PA, etc.) and casing (cast iron, cast aluminium, ductile iron, ceramics, etc.).

As a best practice rule with regard to surface roughness, each contact surface of housing, centerplate and the cover plate should be not more than 1.6Ra. Each contact surface of inner and outer gear and housing, centre plate and cover plate should be kept $0.1 \mathrm{Ra} \div$ 0.25Ra.
\end{abstract}

\title{
4.3. The limitations
}

\subsubsection{The leakage}

Major internal pump leakages are across the faces and through tip-to-tip. The basic hydrodynamic lubrication theory applies that both of them are proportional to the 
pressure drop and the cube of the axial clearance. These basic relations give a substantial idea of the importance of clearance on leakage because, for instance, if the clearances are doubled, the leakage will increase by a factor of eight. Leakage is also inversely proportional to the length of the leak path and the fluid viscosity. Then, as shown by Inaguma ${ }^{34}$, higher temperature decreases flow viscosity, and consequently, leakages will increase.

\subsubsection{The friction, wear and hydrodynamic lubrication}

In order to avoid metal-to-metal contact, the trochoidal-gear normally operates with hydrodynamic film supporting the external diameter of the outer gear and faces. On the other hand, one of the factors to the losses of efficiency is caused by friction, wear and viscous drag ${ }^{35-37}$. Viscous losses are increased by large diameter, high speed, tight clearances and high viscosity.

As a best practice rule because the external diameter of the outer gear is the dominant factor, in applications where it is important to keep mechanical losses to a minimum, try to choose a trochoidal-gear set with the smallest external diameter. 
Proc IMechE Part C: J Mechanical Engineering Science

\author{
4.3.3. The cavitation \\ Pump cavitation occurs whenever the local inlet pressure is below the vapour pressure of \\ the fluid ${ }^{38}$. The three major contributors to pump cavitation and the corresponding best \\ practice rules are: \\ - Fluid inlet velocity limitation: in most applications, pump inlet velocity through a \\ line, fitting, or port should be below $2 \mathrm{~m} / \mathrm{sec}$. \\ - Rotation velocity limitation: in order to ensure a well fulfil of the chambers in the \\ gerotor set, the tip speed of the inner gear should be kept below $15 \mathrm{~m} / \mathrm{sec}$. \\ - Suction line losses limitation: the lines should be designed to minimize losses; \\ special care in the line length, diameter and location.
}

\title{
5. Concluding remarks
}

The previous section has introduced concepts, guidelines and best practice rules leading to the following concluding remarks:
a. The gear thickness has a strong influence on the volumetric efficiency (irregularity flow index)
b. The eccentricity has a strong influence on the volumetric capacity 
Proc IMechE Part C: J Mechanical Engineering Science

c. The variation of the external diameter of the outer gear can be achieved by acting on the eccentricity

d. The increase of the tip velocity has a negative effect on the filling

e. The intervention on the shape of the porting it is possible to slightly improve the volumetric efficiency

f. The arc radius of the tooth of the outer gear has a strong influence on the contact stress

g. The volumetric characteristics become better as the number of teeth increases, but the contact stress becomes worse

h. The number of teeth has a strong influence on the volumetric efficiency (irregularity flow index)

i. The even number of chambers have a slight increase of the irregularity of the flow compared to odd number of chambers

j. The filling is slightly improved by axial inlet feeding in the direction of the inlet line

Final remarks: 
Proc IMechE Part C: J Mechanical Engineering Science

- The design of the porting is based on theoretical analysis. A more detailed design of the effective port areas and the existence of relief grooves and their geometry variations in the instantaneous flow of a trochoidal-gear pump should be performed by using a numerical simulation and/or dynamic-system model previous experimental work.

- The design of the porting must search to maximize filling and sealing, minimize face friction, optimize flow ripple by reducing pressure ripple, reduce noise and vibration and keep pressure balance in the trochoidal-gear set ${ }^{39}$.

- Accurate prediction of the pump design effects (flow ripple, leakages, interaction, instability, ...) requires complete system numerical simulation and/or dynamicsystem model previous experimental work ${ }^{40-41}$.

\section{Conclusions}

A designer is knowledgeable of the hydraulic requirements for a specific engineering application and his knowledge could lead him to choose a trochoidal-gear pump owing to its remarkable advantages in front other hydraulic pumps. Nonetheless, the designer could not be an expert in hydraulic pump design. Then, if the trochoidal-gear pump has to 
Proc IMechE Part C: J Mechanical Engineering Science

be designed from the very beginning, from scratch, the review of existing research reveals the significant gaps to realize a new-born project and overcome a vague design due to a lack of knowledge.

Best practice rules to design a trochoidal-gear pump from scratch, drawn on existing research work and the own authors' experience and know-how, has been presented in this paper. As a first step, the conceptual stage leads the designer to obtain a complete trochoidal-gear set by means of four basic parameters well known from engineering application, simple formulae and guidelines. The design process, a step forward, the most important characteristics of the pump such as the porting, the pump construction and the limitations are presented based on significant explanations, meaning of each feature, selection, effects and good practices. Finally, concluding remarks reveals the influence of the main parameters in the pump performance before the decision is taken.

This collection of best practice rules intends to guide the designer taking good decisions early in the design process that limit design change later in the experimental and manufacturing part.

\section{Acknowledgment}


Proc IMechE Part C: J Mechanical Engineering Science

The authors would like to acknowledge the companies AMES Spain and MAVILOR Spain for providing the necessary support.

\section{Declaration of conflicting interests}

The author(s) declared no potential conflicts of interest with respect to the research, authorship, and/or publication of this article.

\section{Funding}

This research program, project DPI2013-42031-P, receives financial support from the Ministry of Economy and Competitiveness of Spain and is co-financed by FEDER founding of European Union (EU); authors acknowledge this financial support. 


\section{References}

1. Ivantysyn J and Ivantysynova M. Hydrostatic pumps and motors. Tech. Books Int., New Deli, India, Chap. 4, 2003.

2. Schweiger $W$, Schoefmann $W$ and Vacca $A$. Gerotor pumps for automotive drivetrain applications: a multi domain simulation approach. SAE Technical Paper 2011. DOI: 10.4271/2011-01-2272.

3. Jamadar M, Jose A, Ramdasi SS and Marathe NV. Development of in-house competency to build compact gerotor oil pump for high speed diesel engine application. SAE Technical Paper 2013. DOI: 10.4271/2013-01-2738,

4. Kamal A, Kaundabalaraman K, Rathi $\mathrm{H}$, et al. Design analysis \& parametric optimization of gerotor oil pump for improving volumetric efficiency. SAE Technical Paper 2016. DOI: 10.4271/2016-28-0113.

5. Hwang YW and Hsieh CF. Geometric design using hypotrochoid and non-undercutting conditions for an internal cycloidal gear. ASME J Mech Des 2006; 129: 413-420. DOI: 10.1115/1.2437806.

6. Chang YJ, Kim JH, Jeon $\mathrm{CH}$, et al. Development of an integrated system for the automated design of a gerotor oil pump. ASME J Mech Des 2007, 129: 1099-1105. DOI: 10.1115/1.2757629.

7. Yang DCH, Yan J, and Tong, SH. Flowrate formulation of deviation function based gerotor pumps. ASME J Mech Des 2010; 132: 064503-1-5. DOI: 10.1115/1.4001595.

8. Bae JH, Kwak HS, San S, et al. Design and CFD analysis of gerotor with multiple profiles (Ellipse-Involute-Ellipse type and 3-Ellipses type) using rotation and translation algorithm. Proc IMechE, Part C: J Mechanical Engineering Science 2015; 0: 1-20. DOI: 10.1177/0954406215583888. 
9. Hao C, Wenming $Y$ and Guangming L. Design of gerotor oil pump with new rotor profile for improving performance. Proc IMechE, Part C: J Mechanical Engineering Science 2015; 0: 1-20. DOI: 10.1177/0954406215618228.

10. Bonandrini K, Mimmi G and Rottenbacher $\mathrm{C}$. Theoretical analysis of internal epitrochoidal and hypotrochoidal machines. Proc IMechE Part C: J Mechanical Engineering Science 2008; 223: 1469-1480. DOI: 10.1243/09544062JMES1163.

11. Bonandrini K, Mimmi G and Rottenbacher $\mathrm{C}$. Theoretical analysis of an original rotary machine. ASME J Mech Des 2010; 132: 024501-8. DOI: 10.1115/1.4000698.

12. Biernacki K. Selection of the optimum tooth profile for plastic cycloidal gears. Proc IMechE, Part C: J Mechanical Engineering Science 2014; 228: 3395-3404. DOI: 10.1177/0954406214531408.

13. Kwon SM, Kang HS and Shin JH. Rotor profile design in a hypogerotor pump. Journal of Mechanical Science and Technology 2009; 23: 3459-3470. DOI: 0.1007/s12206-0091007-y.

14. Heisel $U$ and Mishev A. Development of a new gerotor pump with innovative gerotor design and investigation of its hydraulic characteristics through CFD Analysis. In: The 9th International Fluid Power Conference, IFK, Aachen, Germany, 2014, pp.1-10.

15. Arinaga $\mathrm{S}$, Yoshida $\mathrm{K}$, Takada $\mathrm{S}$, et al. The latest trends in oil pump rotors for automobiles. Sei Technical Review 2016; 82: 59-65.

16. Mancò S, Nervegna N, Rundo, M, et al. Miniature gerotor pump prototype for automotive applications. In: 3rd International Fluid Power Conference, Aachen, Germany, 2002, pp.153-167.

17. Leester-Schädel $M$, Thies JW, Schubert $T$, et al. Rotational micro actuator for microsurgery. Microsyst Technol 2014; 20: 879-888. DOI: 10.1007/s00542-014-2069-z. 
18. Avery $\mathrm{N}$ and Johnston N. Variable displacement gear and gerotor pumps. In: Proceedings of the ASME/BATH 2015 Symposium on Fluid Power and Motion Control, Chicago, Illinois, USA, Paper No.FPMC2015-9527, 2015, pp.1-7. DOI:

10.1115/FPMC2015-9527.

19. Gamez-Montero PJ, Castilla R, Khamashta M, et al. Contact problems of a trochoidalgear pump. International Journal of Mechanical Sciences 2006; 48: 1471-1480. DOI: 10.1016/j.ijmecsci.2006.06.013.

20. Paffoni B, Progri R, and Gras R. Teeth clearance effects upon pressure and film thickness in a trochoidal hidrostatic gear pump. Proc IMechE, Part G: J Aerospace Engineering 2004; 218: 247-256. DOI: 10.1243/0954410041872799

21. Hsieh CF. Influence of Gerotor performance in varied geometrical design parameters. ASME J Mech Des 2009; 131: 121008-7. DOI: 10.1115/1.4000484.

22. Choi TH, Kim MS, Lee GS, et al. Desgin of rotor for internal gear pump using cycloid and circular-arc curves. ASME J Mech Des 2012; 134: 011005-12. DOI:

10.1115/1.4004423.

23. Altare $\mathrm{G}$ and Rundo $\mathrm{M}$. Computational fluid dynamics analysis of gerotor lubricating pumps at high speed: geometric features influencing the filling capability. ASME J Fluids Eng 2016; 138: 111101-11. DOI: 10.1115/1.4033675.

24. Stryczek J, Bednarczyk S and Biernacki K. Strength analysis of the polyoxymethylene cycloidal gears of the gerotor pump. Archives of Civil and Mechanical Engineering 2014; 14: 647-660. DOI: 10.1016/j.acme.2013.12.005.

25. Mancò S, Nervegna $\mathrm{N}$ and Rundo $\mathrm{M}$. Effects of timing and odd/even number of teeth on noise generation of gerotor lubricating pumps for IC engines. SAE Technical Paper 2000. DOI: 10.4271/2000-01-2630. 
26. Gamez-Montero PJ and Codina E. Flow characteristics of a trochoidal-gear pump using bond graphs and experimental measurement. Part 1. Proc IMechE, Part I: J. Systems and Control Engineering 2007; 221: 331-346. DOI: 10.1243/09596518JSCE250.

27. Gamez-Montero PJ, Castilla R, Mujal R, et al. GeroLAB package system: innovative tool to design a trochoidal-gear pump. ASME J Mech Des 2009; 131: 074502-6. DOI: 10.1115/1. 3125889.

28. GeroLAB Package System, 2015, http://www.gerolab.es

29. Gamez-Montero PJ, Garcia-Vilchez M, Raush G, et al. Teeth clearance and relief grooves effects in a trochoidal-gear pump using new modules of GeroLAB. ASME J Mech Des 2012; 134: 054502-7. DOI: 10.1115/1.4006440.

30. Kim SY, Nam YJ and Park MK. Design of port plate in gerotor pump for reduction of pressure pulsation. Journal of Mechanical Science and Technology 2006; 20: 16261637. DOI: 10.1007/BF02916266.

31. Nichols P. Gerotor selection and pump design. Technical Report 2014, Portland, USA.

32. Ivanović $L$, Devedžić $G$, Ćuković $S$, et al. Modeling of the meshing of trochoidal profiles with clearances. ASME J Mech Des 2012; 134: 041003-9. DOI: 10.1115/1.5621.

33. Hsieh CF. Flow Characteristics of gerotor pumps with novel variable clearance designs. ASME J Fluids Eng 2015; 137: 041107-12. DOI: 10.1115/1.4029274.

34. Inaguma Y. 2012, “A practical approach for analysis of leakage flow characteristics in hydraulic pumps. Proc IMechE, Part C: J Mechanical Engineering Science 2012; 227: 980-991. DOI: 10.1177/0954406212456933.

35. Inaguma Y. Friction torque characteristics of an internal gear pump. Proc IMechE, Part C: J Mechanical Engineering Science 2011; 225: 1523-1534. DOI: 10.1177/0954406211399659. 
36. Karamooz Ravari MR. Elliptical lobe shape gerotor pump design to minimize wear. Front Mech Eng 2011; 6: 429-434. DOI: 10.1007/s11465-011-0247-6.

37. Furustig J, Larsson R, Almqvist A, et al. A wear model for EHL contacts in gerotor type hydraulic motors. Microsyst Technol 2014; 20: 879-888. DOI: 10.1007/s00542-0142069-z.

38. Stryczek J, Antoniak $\mathrm{P}$, Jakhno $\mathrm{O}$, et al. Visualisation research of the flow processes in the outlet chamber-outlet bridge-inlet chamber zone of the gear pumps. Archives of Civil and Mechanical Engineering 2014; 15: 95-108. DOI: 10.1016/j.acme.2014.02.010.

39. Hsieh CF and Hwang YW. 2007. Geometric design for a gerotor pump with high area efficiency. ASME J Mech Des 2007; 129: 1269-1277. DOI: 10.1115/1.2779887.

40. Pellegri M, Vacca A, Frosina E, et al. Numerical analysis and experimental validation of Gerotor pumps: A comparison between a lumped parameter and a computational fluid dynamics-based approach. Proc IMechE, Part C: J Mechanical Engineering Science 2016; 0: 1-18. DOI: 10.1177/0954406216666874.

41. Raush G, Gamez-Montero PJ, Castilla R, et al. Experimental study on the impulsion port of a trochoidal wheeled pump. Flow Measurement and Instrumentation 2016; 0: 1-23. DOI: http://dx.doi.org/10.1016/j.flowmeasinst.2016.10.014.

\section{Nomenclature}

Notation

$\begin{array}{ll}c_{v} & \text { volumetric capacity } \\ D_{c} & \text { external diameter of the outer/external gear } \\ e & \text { eccentricity }\end{array}$




\begin{tabular}{ll}
$G$ & external porting radius \\
$H$ & trochoidal-gear thickness \\
$N$ & theoretical power \\
$R i R i$ & internal porting radius \\
$R L$ & theoretical radial load \\
$S$ & arc radius of the outer gear tooth \\
$T$ & theoretical torque \\
$V t$ & tip velocity of the internal gear \\
\hline$W C$ & wall wide of the outer gear \\
\hline$Z$ & number of teeth of the outer gear \\
\hline & tooth profile height correction coefficient
\end{tabular}

http://mc.manuscriptcentral.com/(site) 


\section{List of Figure Captions}

Figure 1. The basic geometrical parameters of the trochoidal-gear.

Figure 2. The function of the porting.

Figure 3. The theoretical porting (a) and the former porting (b).

Figure 4. The outlet and the inlet metering porting.

Figure 5. The porting depth variation.

Figure 6. The metering porting (a) and the shadow porting on the cover plate (b) where an inlet meeting groove is also machined.

Figure 7. The pressure balance.

Figure 8. The undercut in the housing and the chamfer in the gear [mm].

Figure 9. The special rim that generates an extra pressure force reducing clearances. 
Proc IMechE Part C: J Mechanical Engineering Science

1

2

3

4

5

6

7

8

9

10

11

12

13

14

15

16

17

18

19

20

21

22

23

24

25

26

27

28

29

30

31

32

33

34

35

36

37

38

39

40

41

42

43

44

45

46

47

48

49

50

51

52

53

54

55

56

57

58

59

60

\section{Table Caption List}

Table 1. Basic guidelines to conventional operating conditions and clearances.

http://mc.manuscriptcentral.com/(site) 


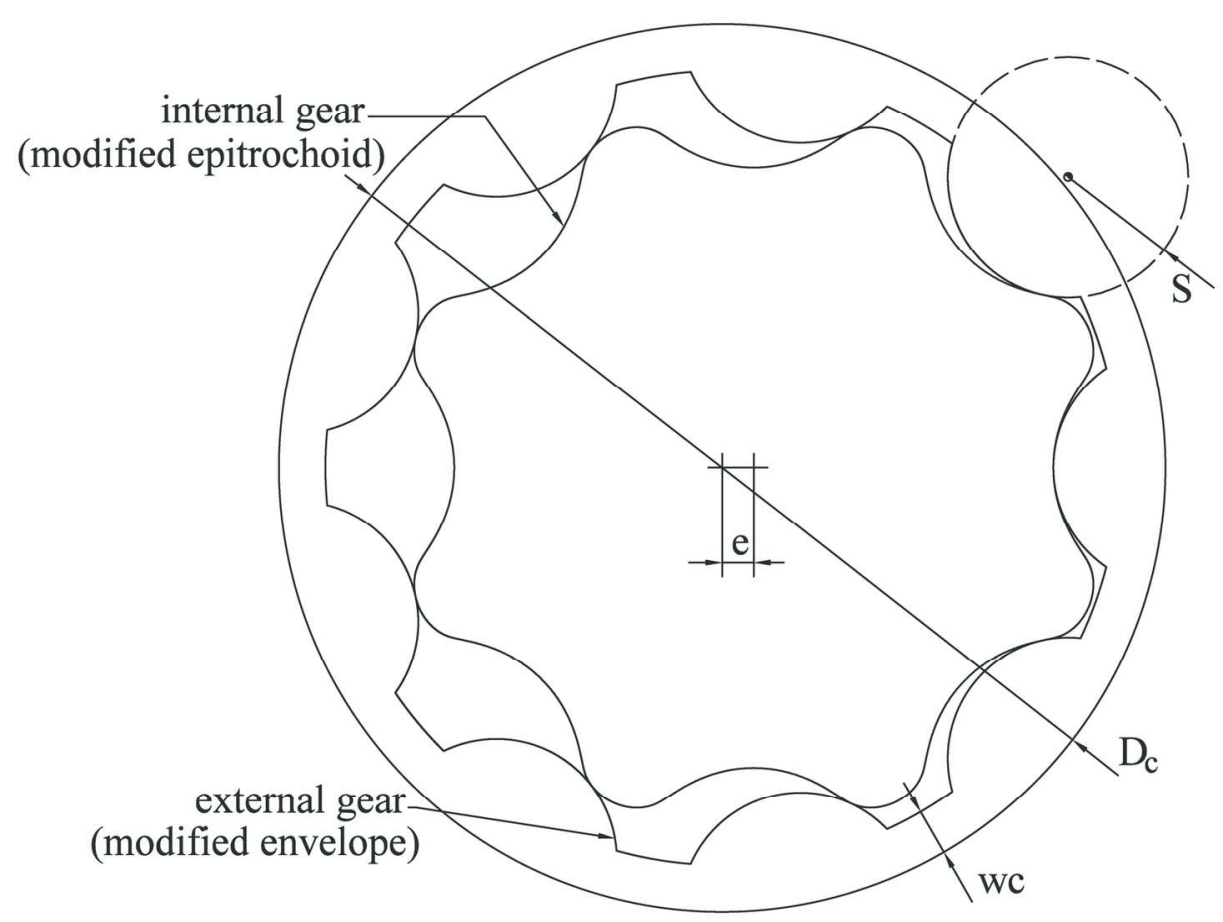

The basic geometrical parameters of the trochoidal-gear.

$152 \times 111 \mathrm{~mm}(300 \times 300 \mathrm{DPI})$ 


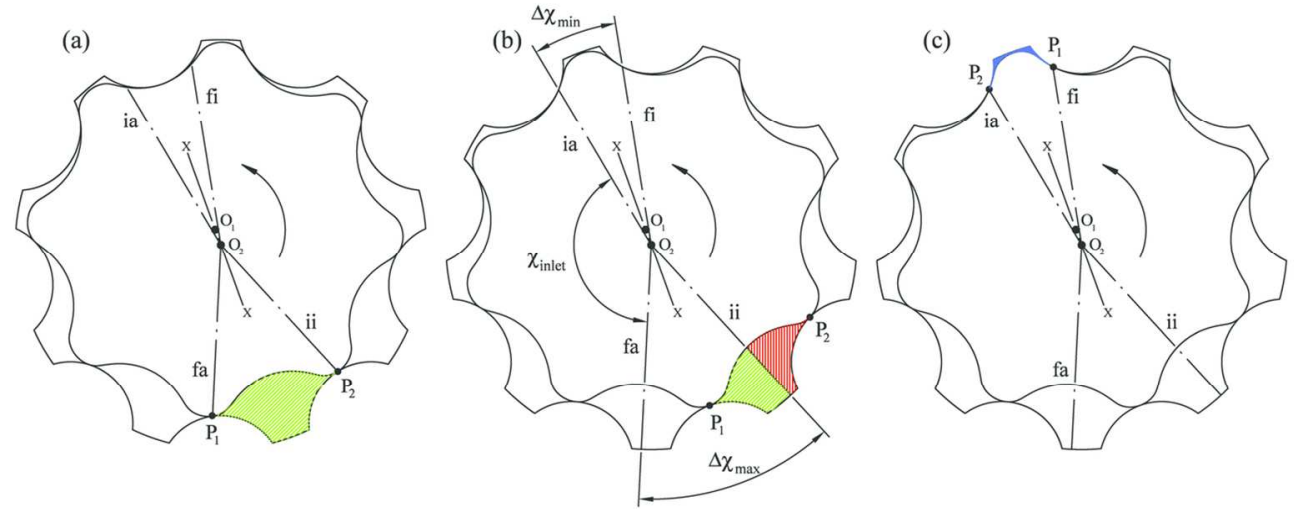

The function of the porting.

$118 \times 48 m m(300 \times 300$ DPI $)$ 


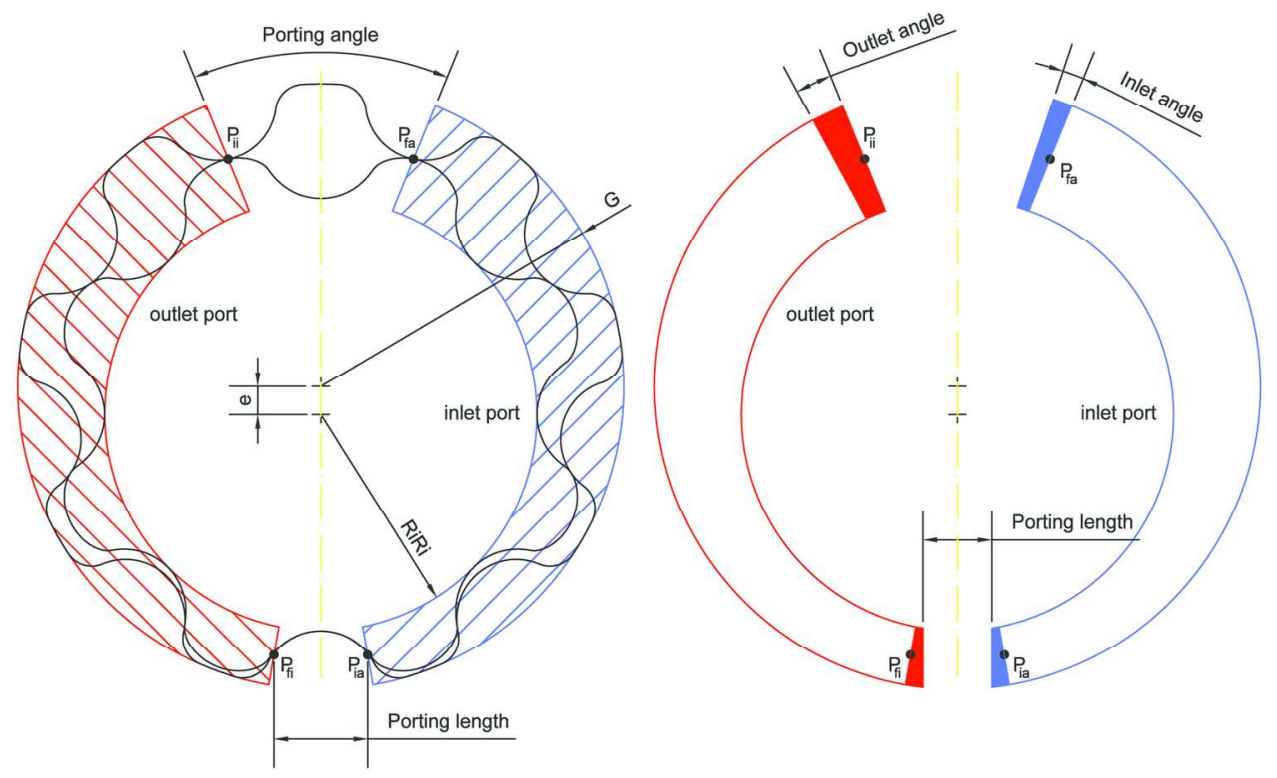

The theoretical porting (a) and the former porting (b).

$155 \times 96 \mathrm{~mm}(300 \times 300 \mathrm{DPI})$ 


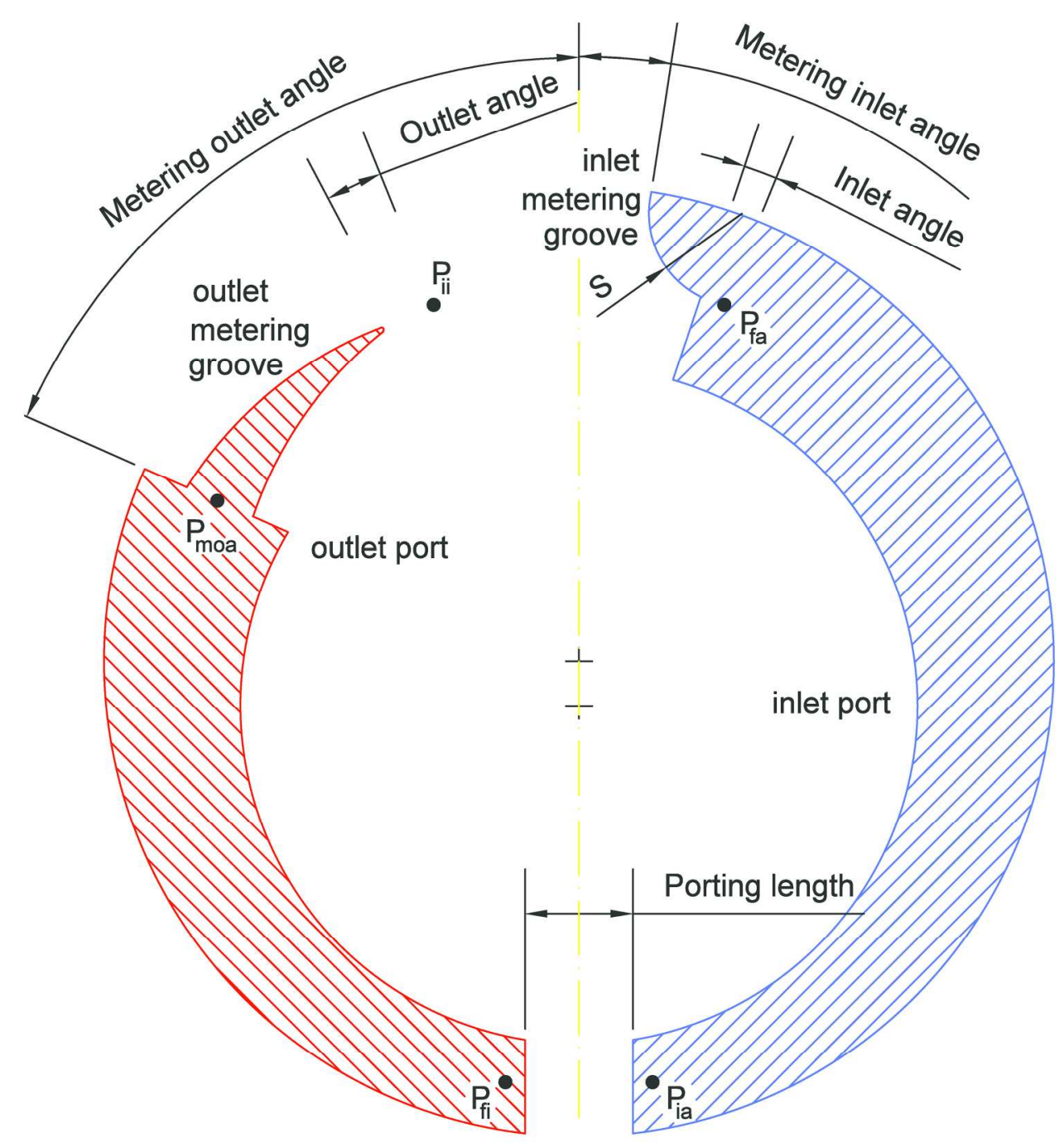

The outlet and the inlet metering porting.

$190 \times 203 \mathrm{~mm}(300 \times 300$ DPI $)$

http://mc.manuscriptcentral.com/(site) 


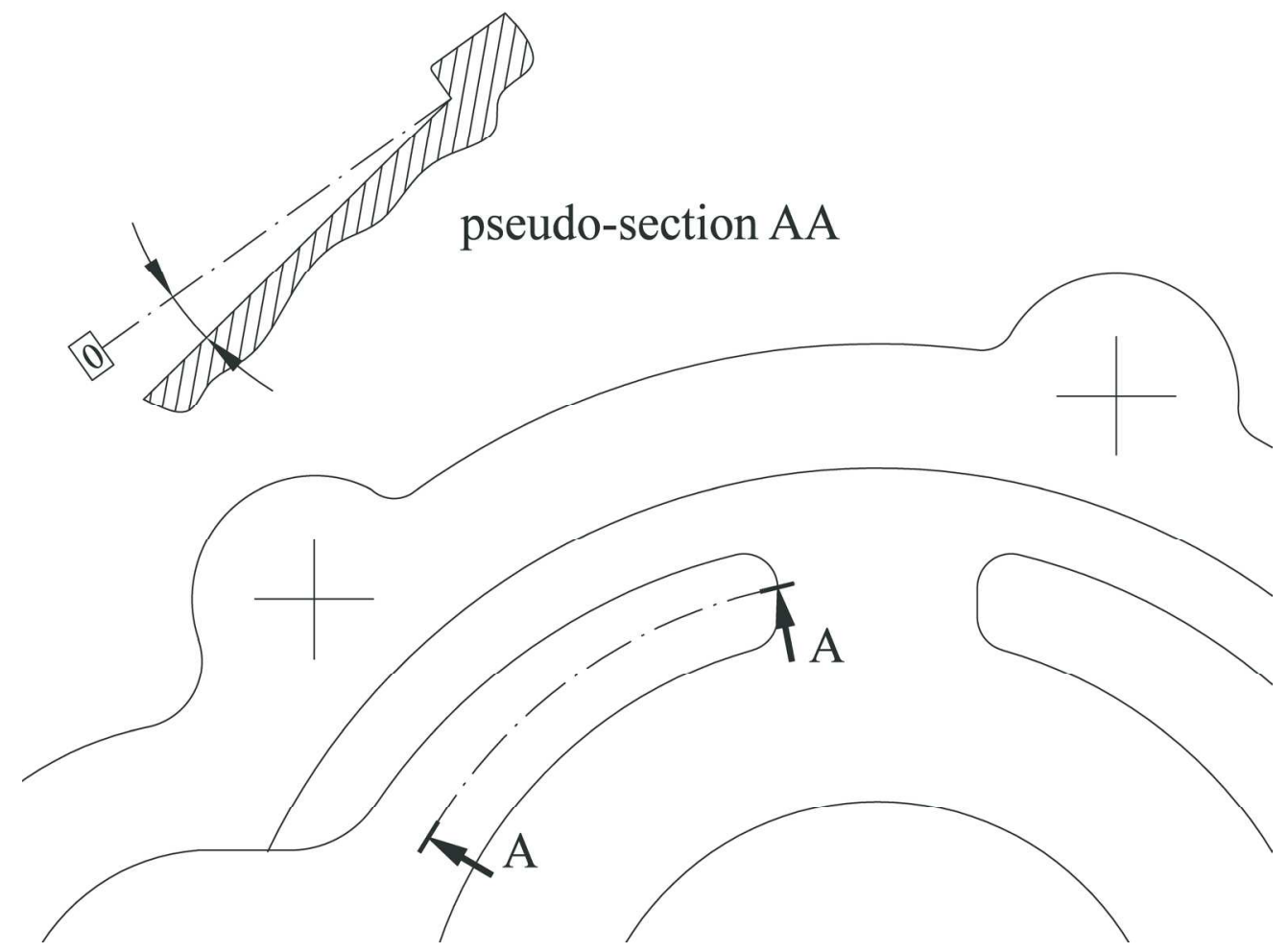

The porting depth variation.

$180 \times 135 \mathrm{~mm}(300 \times 300$ DPI $)$ 


1
2
3
4
5
6
7
8
9
10
11
12
13
14
15
16
17
18
19
20
21
22
23
24
25
26
27
28
29
30
31
32
33
34
35
36
37
38
39
40
41
42
43
44
45
46
47
48
49
50
51
52
53
54
55
56
57
58
59
60

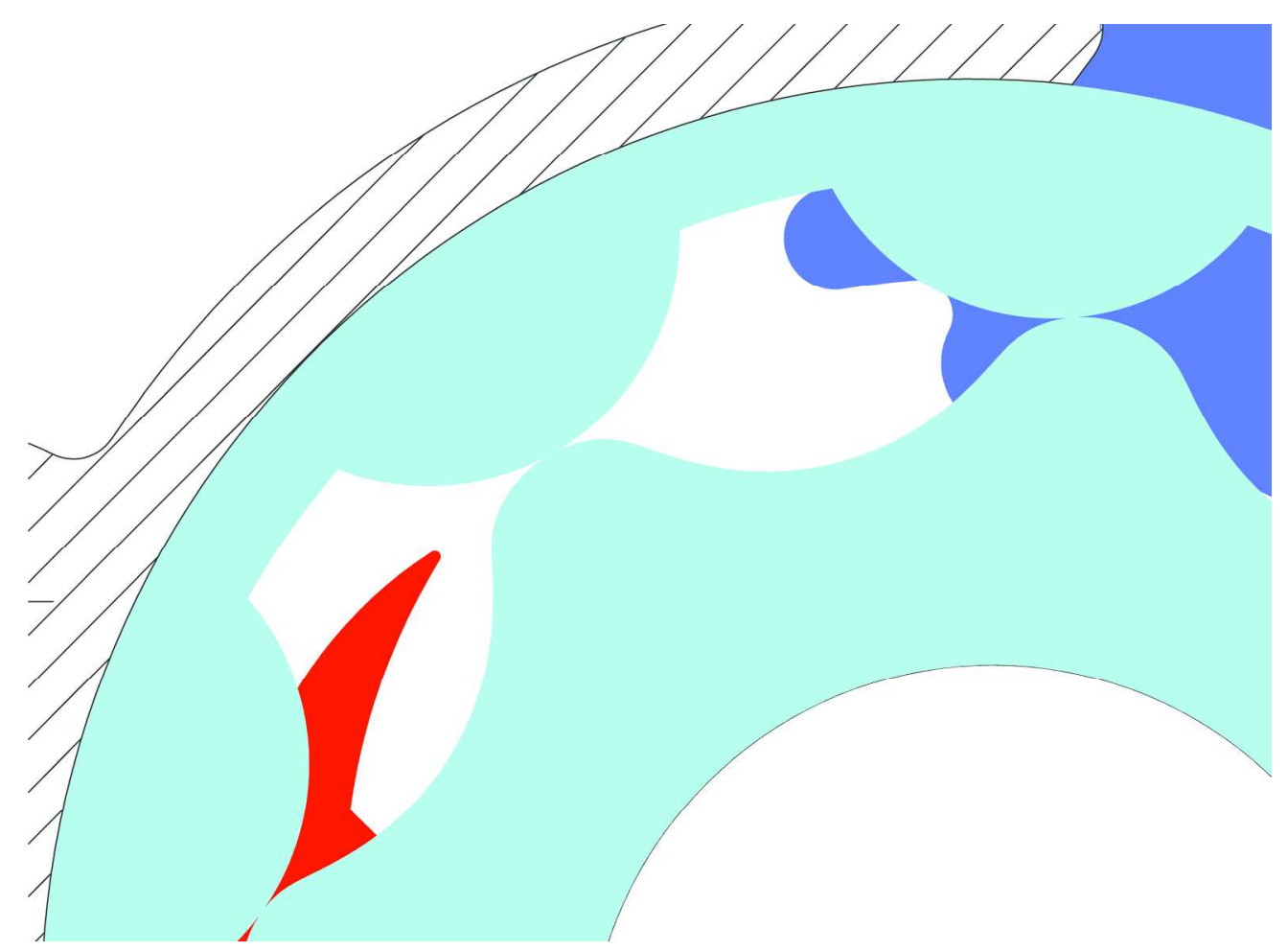

The metering porting (a) and the shadow porting on the cover plate (b) where an inlet meeting groove is also machined.

$202 \times 148 m m(300 \times 300$ DPI $)$ 
1

2

3

4

5

6

7

8

9

10

11

12

13

14

15

16

17

18

19

20

21

22

23

24

25

26

27

28

29

30

31

32

33

34

35

36

37

38

39

40

41

42

43

44

45

46

47

48

49

50

51

52

53

54

55

56

57

58

59

60

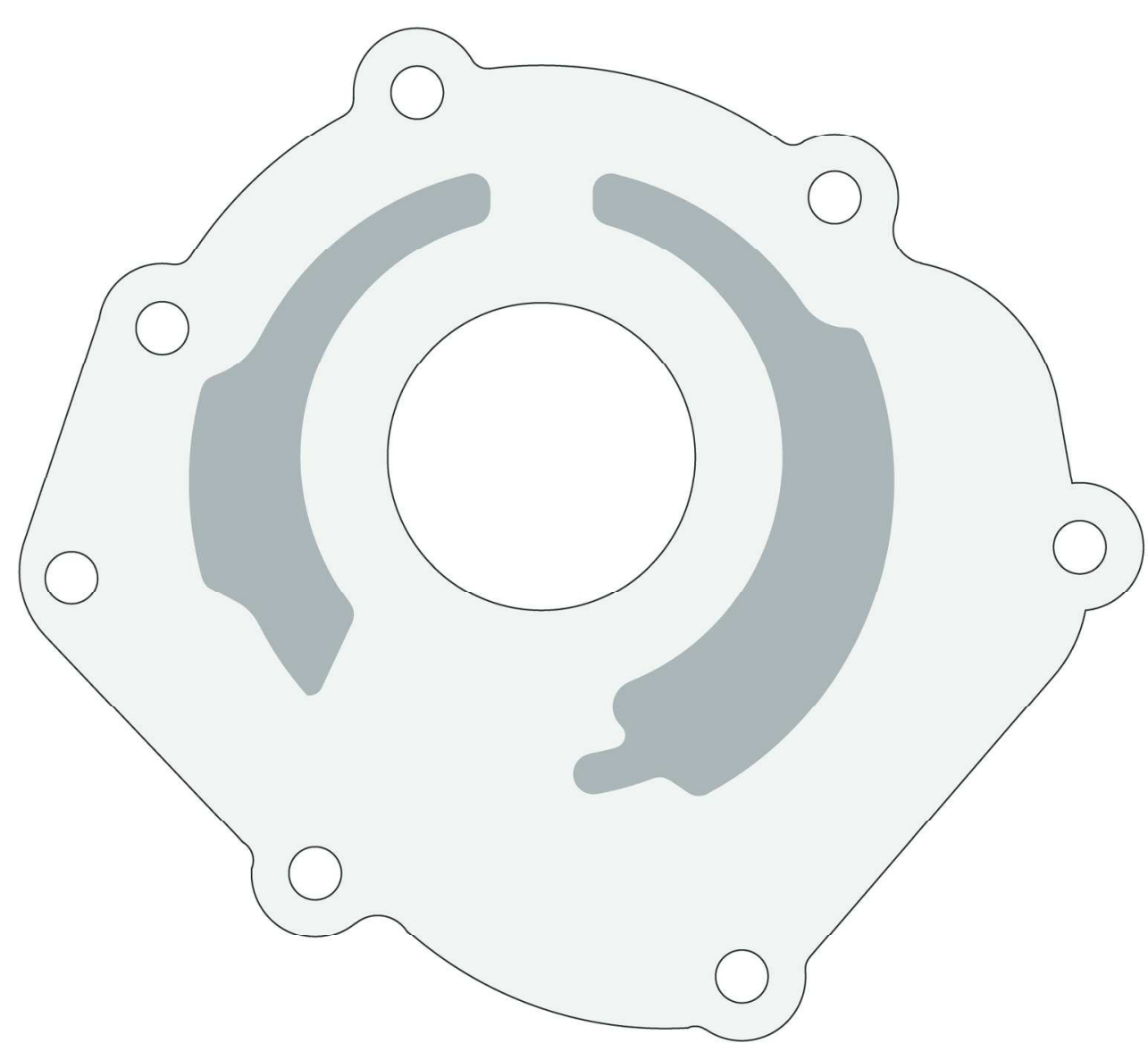

The metering porting (a) and the shadow porting on the cover plate (b) where an inlet meeting groove is also machined.

$193 \times 171 \mathrm{~mm}(300 \times 300 \mathrm{DPI})$ 


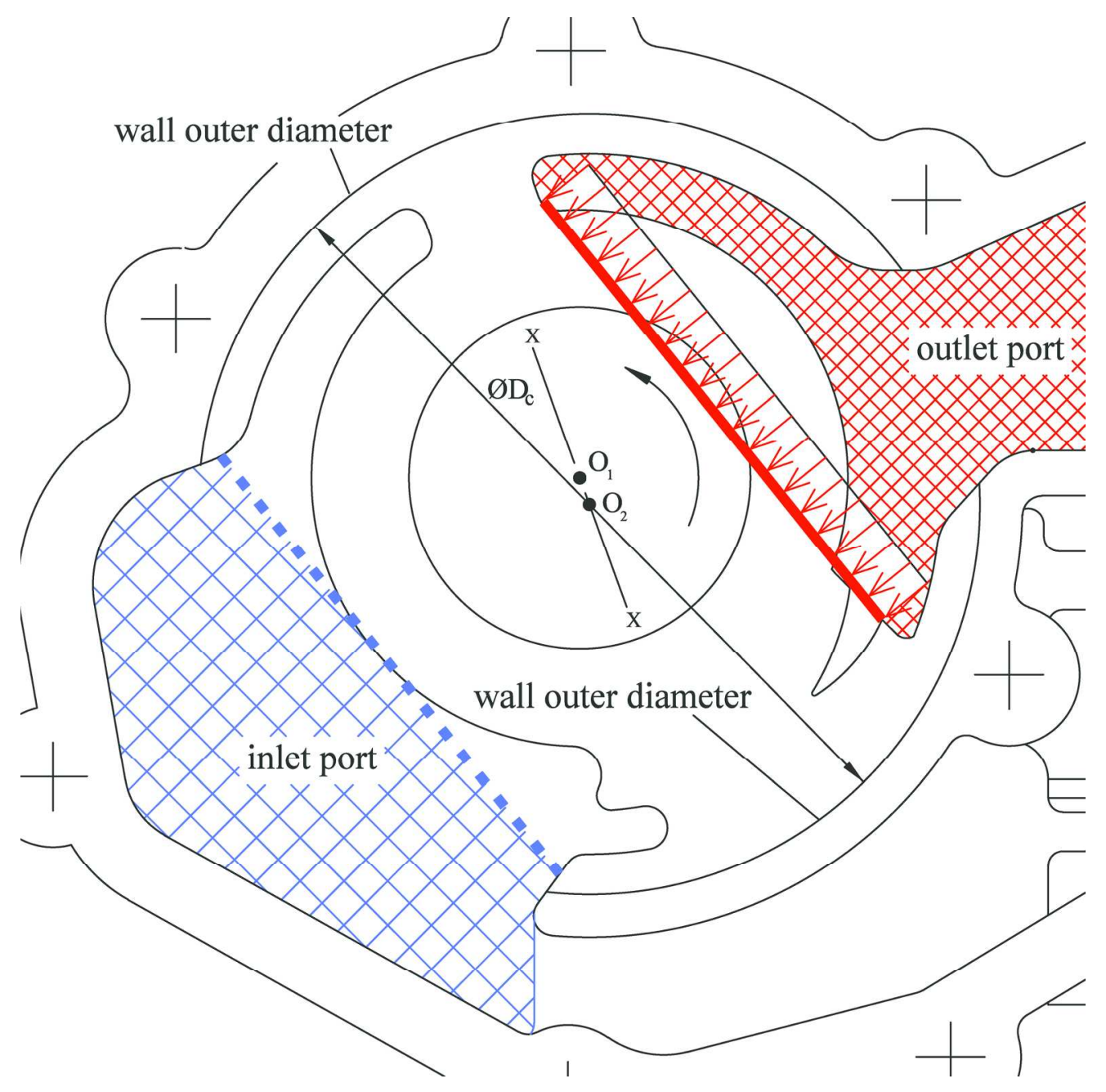

The pressure balance.

$176 \times 175 \mathrm{~mm}(300 \times 300$ DPI $)$

http://mc.manuscriptcentral.com/(site) 


1
2
3
4
5
6
7
8
9
10
11
12
13
14
15
16
17
18
19
20
21
22
23
24
25
26
27
28
29
30
31
32
33
34
35
36
37
38
39
40
41
42
43
44
45
46
47
48
49
50
51
52
53
54
55
56
57
58
60

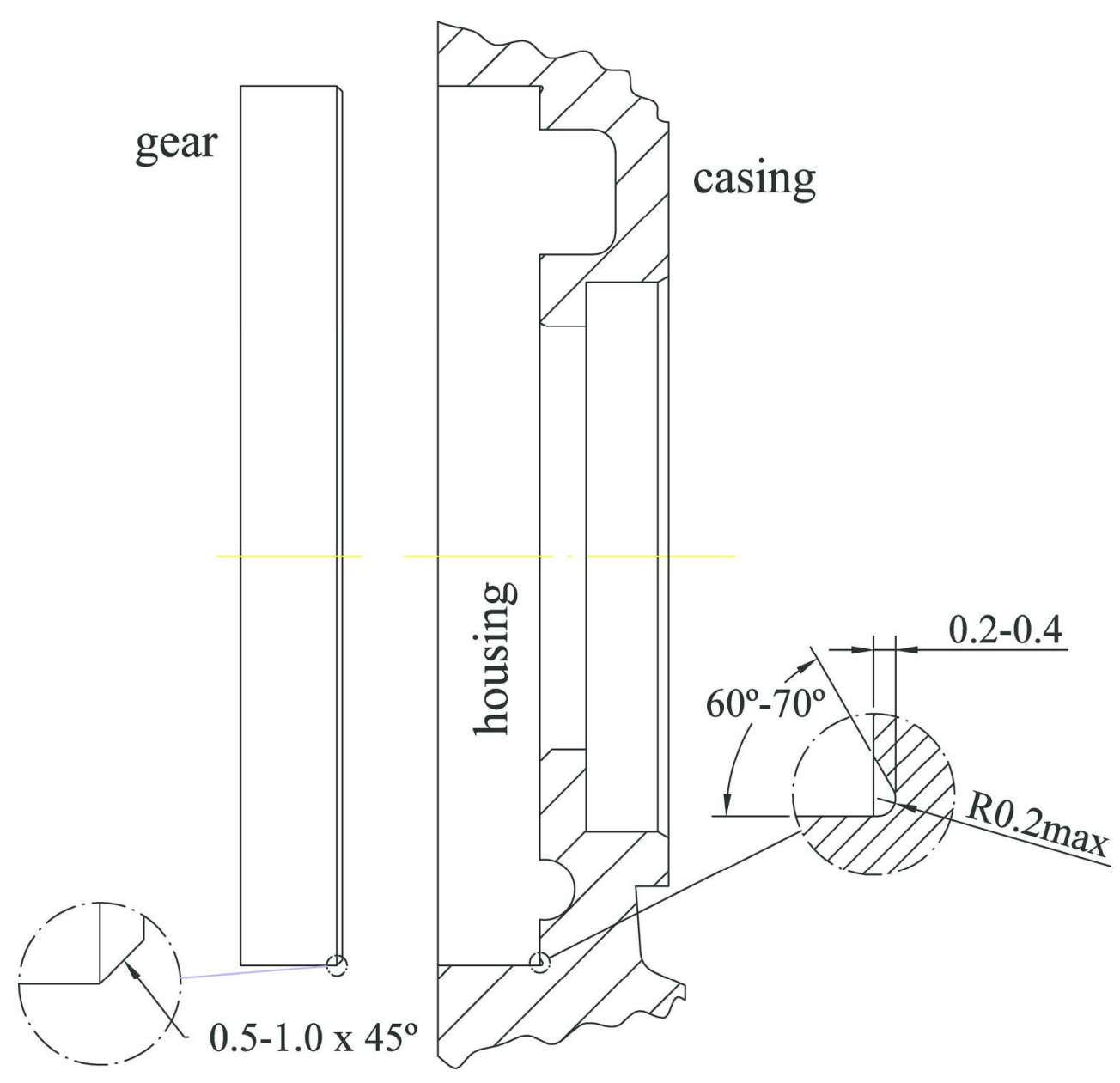

The undercut in the housing and the chamfer in the gear [mm].

$191 \times 185 \mathrm{~mm}(300 \times 300 \mathrm{DPI})$

http://mc.manuscriptcentral.com/(site) 


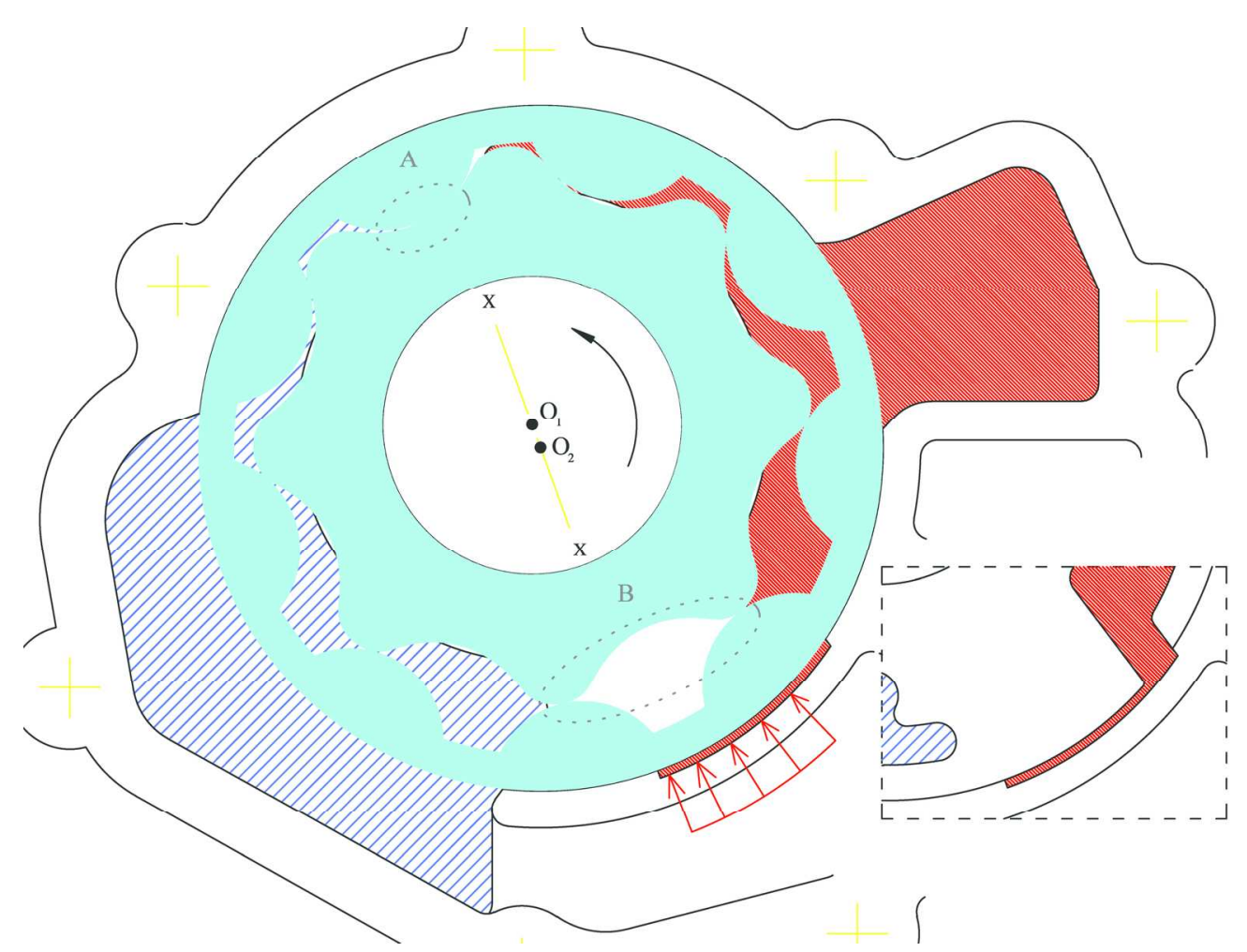

The special rim that generates an extra pressure force reducing clearances.

$167 \times 125 \mathrm{~mm}(300 \times 300 \mathrm{DPI})$

http://mc.manuscriptcentral.com/(site) 
Table 1. Basic guidelines to conventional operating conditions and clearances.

\begin{tabular}{lll}
\hline Parameter & Low Pressure & High Pressure \\
\hline Pressure [MPa] & $0.3 \div 1.0$ & $1.0 \div 6.0$ \\
Rotational velocity [rpm] & $500 \div 10000$ & $1500 \div 3500$ \\
Volumetric capacity [cc/rev] & $3.0 \div 15.0$ & $9.0 \div 20.0$ \\
Axial face clearance $[\mathrm{mm}]$ & $0.05 \div 0.10$ & $0.005 \div 0.030$ \\
Tip-to-tip clearance $[\mathrm{mm}]$ & $0.08 \div 0.20$ & 0.08 max. \\
Eccentricity tolerance $[\mathrm{mm}]$ & \pm 0.05 & \pm 0.02 \\
External outer diameter clearance $[\mathrm{mm}]$ & $0.10 \div 0.20$ & $0.08 \div 0.14$
\end{tabular}

Basic guidelines to conventional operating conditions and clearances.

$82 \times 45 \mathrm{~mm}(600 \times 600 \mathrm{DPI})$ 